\title{
Health-related quality of life of cancer patients undergoing radiotherapy
}

\author{
Qualidade de vida relacionada à saúde de pacientes com câncer em tratamento \\ radioterápico
}

\section{Calidad de vida relacionada con la salud de pacientes con cáncer en tratamiento de radioterapia}

Juliana Maria de Paula ${ }^{1}$, Namie Okino Sawada ${ }^{2}$

Objective: to evaluate the health-related quality of life of patients with head and neck cancer during radiotherapy treatment. It was carried out with 41 patients between 2009-2010 in central radiotherapy. Methods: this is a longitudinal study. It was used the Functional Assessment Cancer Therapy Head and Neck. The predominance of cases were male, with a mean age of 62 years. Results: in the 5 domains assessed, the one that was more affected was the "physical well-being", which is directly related to the side effects of treatment. Conclusion: the symptoms caused by the treatment are negatively associated with the Quality of Life Related to Health Care, so it is important that the health care team assess and identify the needs of the patient, allowing him to have a monitor that meets your needs and minimize symptoms.

Descriptors: Quality of Life; Head and Neck Neoplasms; Radiotherapy; Oncology Nursing.

Objetivo: avaliar a qualidade de vida relacionada à saúde de pacientes com câncer de cabeça e pescoço durante o tratamento radioterápico. Método: estudo longitudinal realizado com 41 pacientes entre 2009-2010 na central de radioterapia. Utilizouse o instrumento Functional Assessment Cancer Therapy Head and Neck. A predominância dos casos foi do sexo masculino, com a média de idade de 62 anos. Resultados: dos 5 domínios avaliados, o que mais foi afetado "bem-estar físico", o qual está diretamente relacionado com os efeitos colaterais decorrentes do tratamento. Conclusão: os sintomas causados pelo tratamento interferem negativamente na Qualidade de Vida Relacionada à Saúde, portanto, é importante que a equipe de saúde avalie e identifique as necessidades do paciente, permitindo que ele tenha um acompanhamento que atenda suas necessidades e minimizem os sintomas.

Descritores: Qualidade de Vida; Neoplasias de Cabeça e Pescoço; Radioterapia; Enfermagem Oncológica.

Objetivo: estudio prospectivo, con objetivo de evaluar la calidad de vida relacionada con la salud de pacientes con cáncer de cabeza y cuello durante el tratamiento de radioterapia. Método: se realizó con 41 pacientes entre 2009-2011 en dos centros de radioterapia. Se utilizó el instrumento Functional Assessment Cancer Therapy Head and Neck. El predominio de los casos fue del sexo masculino, con edad media de 62 años. Resultados: de los 5 dominios evaluados, lo más afectado fue "bienestar físico", directamente relacionado con los efectos secundarios del tratamiento. Conclusión: los síntomas ocasionados por el tratamiento interfieren negativamente en la Calidad de Vida relacionada con la salud, por lo tanto, es importante que el equipo de atención de la salud evalúe e identifique las necesidades del paciente, lo que permite tener seguimiento que responda a sus necesidades y reduzca al mínimo los síntomas.

Descriptores: Calidad de Vida; Neoplasias de Cabeza y Cuello; Radioterapia; Enfermería Oncológica.

\footnotetext{
${ }^{1}$ Universidade de São Paulo. Ribeirão Preto, SP, Brazil

Corresponding author: Namie Okino Sawada

Av. dos Bandeirantes, 3900. Cidade Universitária, CEP: 14040-902. Ribeirão Preto, SP, Brazil. E-mail: sawada@eerp.usp.br
} 


\section{Introduction}

The Estimates for Incidence of Cancer in Brazil for 2014 indicate the occurrence of approximately 576,000 new cases of cancer, including cases of nonmelanoma skin cancer, emphasizing the scale of the problem of cancer in Brazil ${ }^{(1)}$.

Cancers of the head and neck are placed fifth in the list of the most frequent neoplasias ${ }^{(1-3)}$. In Brazil, the estimate for cancer of the oral cavity in 2014 is 11,280 new cases in men, and 4010 cases in women. These values correspond to an estimated risk of 11.54 new cases per 100,000 men, and 3.92 per 100,000 women ${ }^{(1)}$.

The majority of epithelial tumors are classified as squamous cell cancer of the head and neck, and the anatomical sites which are included in this group cover the oral cavity, pharynx, and larynx, with approximate occurrence of $40 \%, 15 \%$ and $25 \%$, respectively ${ }^{(2)}$.

Surgery on the head and neck involves major resections, and functional and esthetic mutilations occur, with repercussions for the patients' daily lives. Other treatments used for this type of cancer are radiotherapy and chemotherapy, which are commonly used as adjuvant, with the objective of inhibiting the metastases and improving the survival rate ${ }^{(4)}$.

Radiotherapy has three main objectives - cure, remission, and relief of symptoms. When radiotherapy is used to extinguish the entire tumor, it is termed curative; when the objective is to reduce part of the tumor, or to complement the chemotherapy and surgical treatment, it is described as that likely to produce remission, while the objective of symptomatic radiation is to reduce localized pain ${ }^{(5)}$.

Radiotherapy treatment, in spite of presenting the advantage of preserving the structure of the tissues, can entail adverse reactions manifested in the buccal cavity, resulting in harm to the salivary gland, the oral mucosa, and the alveolar bone. Among the main clinical consequences of the localized effects, one finds xerostomia, dermatitis, mucositis, hypogeusia, osteoradionecrosis, fibrosis and trismus ${ }^{(6)}$. These reactions resulting from the treatment entail impairment of the patients' quality of life, and may also influence their conduct and their adherence to the treatment.

The term Health-Related Quality of Life is evidenced in the literature as synonymous withperceived state of health, and has as its main objective to ascertain the extent to which the chronic disease or state - in addition to the symptoms - comes to interfere in an individual's life; Health-Related Quality of Life, therefore, may be defined as Quality of Life within the context of health ${ }^{(7-8)}$.

Both the disease and its frequent treatment produce significant morbidities which gradually compromise the patients' Health-Related Quality of Life; the evaluation, therefore, becomes necessary as it is an important indicator of the influence of the treatment's side effects on the individual. The accurate evaluation of the Health-Related Quality of Life is very important over the course of the radiotherapy treatment, in order to identify the principal symptoms which interfere with the patient's routine, and to provide multidisciplinary monitoring so as to mitigate these symptoms and to ensure the patient's good adherence to the treatment and a good Health-Related Quality of Life during the same.

In the light of the above, this study aimed to evaluate the health-related quality of life in patients with head and neck cancer, undergoing radiotherapy treatment, at the beginning, middle and end of the treatment.

\section{Method}

This is a descriptive and exploratory longitudinal study, undertaken with 41 patients between February 2009 and July 2010, including all patients who began treatment in this data collection period.

The version of the Functional Assessment of Cancer Therapy - Head and Neck version instrument (FACT H\&N) validated for use in the Brazilian 
culture $^{(9)}$ was used for data collection, for specific use in patients with head and neck cancer, for evaluating the Health-Related Quality of Life. It was applied in the form of an interview.

TheFACT H\&Nis a specific and multidimensional instrument, applied in the form of a questionnaire, which evaluates five areas: physical well-being (seven items), social/family well-being (seven items), emotional well-being (six items), functional wellbeing (seven items), and some additional information (11 items), in a total of 38 items. It is a Likert-type scale, (likert) in which the scores vary from not at all (score 1 ) to very much (score 5 ). The higher the score, the better the positivity in relation to the domain measured.

The application of the instrument occurred at three points of the first cycle of radiotherapy (baseline), in the beginning, middle (approximately in the $15^{\text {th }}$ session) and end of the treatment (after the $30^{\text {th }}$ session), in order to evaluate the HealthRelated Quality of Life. All the patients in this sample answered the instrument at the three points; there was no loss of subjects through death or withdrawal from participation in the study.

The study was undertaken in the Radiotherapy Center of a public hospital in the municipality of Ribeirão Preto (in the state of São Paulo), where the outpatient attendance was undertaken, through consultations, examinations, treatment and monitoring of adult patients with cancer, attended through the Unified Health System, private healthcare schemes, and private treatment, in the city of Ribeirão Preto and the surrounding region.

The inclusion criteria were: to be aged over 18 years old, of either sex, diagnosed with cancer of the head and neck, attended in the radiotherapy center of a public hospital in the municipality of Ribeirão Preto, and to be initiating radiotherapy treatment. Patients with other diagnoses and/or other cancers were excluded, as were those with some difficulty in understanding the questions evaluated through simple questions which indicate orientation in time and space, such as date of birth, address, day of the week and others.

The Statistical Package for the Social Sciences, version 15.0, was used for analysis of the data; the Cronbach alpha test for internal consistency was used for testing the reliability of the instrument. Descriptive statistics were undertaken for analyzing the sociodemographic-clinical data, and each domain of the FACT H\&N was analyzed in isolation with the respective syntaxes. The Student t-test was also applied in order to ascertain whether there was a statistically significant difference in the three points at which the instrument was applied.

The research project was approved by the Research Ethics Committee, and confidentiality was maintained regarding the patients' identity, thus respecting Resolution $\mathrm{n}^{0}$ 196/96, of the Brazilian National Health Council, under protocol ${ }^{\circ} 3572 / 2008$. All participants signed two copies of the terms of consent, one being handed to the participant, and the other remaining in the possession of the researcher.

\section{Results}

Of the 41 people with cancer and receiving treatment, male patients predominated (85.4\%), and the mean age was 62 years old. Regarding origin, $19(46.3 \%)$ patients are from Ribeirão Preto and 22 (53.7\%) from other municipalities. Regarding occupational activity, 17 (41.5\%) were retired, 06 (14.6\%) were housewives/househusbands, 09 (22.0\%) farmworkers, and the others undertook various functions. In relation to religion, the majority, 34 (82.9\%) were Roman Catholics.

In relation to clinical and therapeutic data, the most frequent medical diagnoses, according to the Classification of Malignant Tumors ${ }^{(10)}$ were: carcinoma of the oropharynx (46.3\%), carcinoma of the larynx (26.8\%), carcinoma of the oral cavity $(19.5 \%)$ and carcinoma of the maxillary sinuses (7.3\%). Regarding the types of treatment, 23 (56.1\%) had undertaken surgery at least 20 months previously; 
in 09 (21.9\%), the total removal of the affected organ was undertaken, through total laryngectomy. All of the patients undertook radiotherapy, completing 30 sessions. Regarding chemotherapy, 23 (56.1\%) received this treatment (Table 1 ).

Table 1 - Distribution of the 41 patients by age, sex, primary tumor and treatment

\begin{tabular}{lc}
\hline Variables & $\mathbf{n}(\%)$ \\
\hline Age (years) & $7(17.1)$ \\
30 - 50 & $20(48.7)$ \\
$51-70$ & $14(34.1)$ \\
71 - 90 & \\
Sex & $35(85.3)$ \\
Male & $6(14.6)$ \\
Female & \\
Primary tumor & $19(46.3)$ \\
Oropharynx & $11(26.8)$ \\
Larynx & $8(19.5)$ \\
Oral cavity & $3(7.3)$ \\
Maxillary sinuses & \\
Treatment & $9(21.9)$ \\
Radiotherapy & $9(21.9)$ \\
Radiotherapy/surgery & $9(21.9)$ \\
Radiotherapy/chemotherapy & $14(34.1)$ \\
Radiotherapy/chemotherapy/surgery & \\
\hline
\end{tabular}

In order to test the internal consistency of the FACT H\&N, the alpha Cronbach test was applied, with the result of $\alpha=0.89$, demonstrating that the instrument is reliable in this sample.

There was a decrease in the means of all the scales at the different points of application of the FACT $\mathrm{H} \& \mathrm{~N}$ Quality of Life instrument, evidencing that there is a worsening of Health-Related Quality of Life during the radiotherapy treatment (Table 2).
Table 2 - Descriptive statistics (mean and standard deviation) of the scales of the FACT H\&N instrument, at the three points of application (beginning, middle and end of radiotherapy treatment)

\begin{tabular}{lccc}
\hline \multirow{2}{*}{ Domains of the Scale } & \multicolumn{3}{c}{ Time of treatment } \\
\cline { 2 - 4 } & $\begin{array}{c}\text { Beginning } \\
\text { Mean (DP) }\end{array}$ & $\begin{array}{c}\text { Middle } \\
\text { Mean (DP) }\end{array}$ & $\begin{array}{c}\text { End Mean } \\
\text { (DP) }\end{array}$ \\
\hline Physical well-being & $3.16(1.05)$ & $3.08(0.98)$ & $2.97(0.99)$ \\
Social/family well-being & $2.99(0.88)$ & $2.98(0.88)$ & $2.96(0.92)$ \\
Emotional well-being & $3.29(0.91)$ & $3.17(0.98)$ & $3.15(0.89)$ \\
Functional well-being & $2.39(0.97)$ & $2.27(0.93)$ & $2.27(0.91)$ \\
Additional concerns & $2.62(1.04)$ & $2.50(0.94)$ & $2.45(0.92)$ \\
\hline
\end{tabular}

In evaluating specific points of quality of life over the course of the treatment, we ascertained that there were significant variations between the first and second, the first and the third, and the second and the third applications of the FACT H\&N, which demonstrates that Health-Related Quality of Life is impairedduring the course of the radiotherapy treatment (Table 3).

Table 3 - Statistical values of the three points at which the FACT H\&N was applied during the radiotherapy treatment

\begin{tabular}{lcc}
\hline Points of application of the FACT H\&N & t value & $\mathbf{p}$ \\
\hline First-second & 3.416 & $0.002^{*}$ \\
First-third & 3.476 & $0.001^{*}$ \\
Second-third & 2.111 & $0.042^{*}$ \\
\hline${ }^{*} \mathrm{p} \leq 0.001$ & &
\end{tabular}




\section{Discussion}

The greatest prevalence of cancer of the head and neck occurred in the male sex, among ages over 50 years old, corroborating the literature(11-13). Nevertheless, the estimates indicate a decline in the rates of mortality in the male population. This behavior is not yet observed in the women, as a result of the initiation of tobacco use occurring later than among men ${ }^{(1)}$.The main risk factors for cancer of the oral cavity are smoking, drinking alcohol, and infections resulting from HPV. The habit of smoking and drinking establishes synergism between these two risk factors, increasing the risk of developing this type of cancer by a factor of 30 . Tobacco is responsible for approximately $42 \%$ of deaths from this neoplasia. Heavy drinking, on the other hand, corresponds to approximately $16 \%$ of the deaths ${ }^{(1)}$.

One can observe in this study that the minority of patients $9(22.0 \%)$ had only radiotherapy as treatment, and the majority of the patients had radiotherapy associated with chemotherapy and/ or surgery. The combination of radiotherapy with chemotherapy aims to preserve the organs, although there are numerous side effects. The most common side effects resulting from antineoplastic treatment for the oral region are mucositis, xerostomia, dysgeusia, fungal, bacterial and viral infections, radiation caries, trismus, osteoradionecrosis and neurotoxicity ${ }^{(14)}$.

All these associated effects, mainly dysgeusia, dysphagia, xerostomia and mucositis, cause the patient to suffer changes in her nutritional conditions, due to reduction in the sense of taste, reduction in salivation, and pain. Pain is a trivial factor in the difficulty faced by the patient in eating, hydration and speaking. This being the case, if the pain is persistent, it can lead to weight loss, anorexia, cachexia and dehydration ${ }^{(6)}$.

The oral complications also lead to a negative relation in physical appearance and difficulty in communication and respiration, being able to cause changes in mood, resulting in anxiety and depression, directly compromising this patient's Health-Related
Quality of Life, and adherence to the treatment may also be impaired ${ }^{(11,15)}$.In accordance with the data obtained through the literature, one can perceive the need for multidisciplinary action with the patient with cancer of the head and neck.

In one study undertaken with patients with cancer of the larynx, it was evidenced that the patients referred to other multi-professional services, in this case speech therapy and nutrition, presented better Health-Related Quality of Life ${ }^{(16)}$.In the light of this, it is important to consider the Nurse's direct functioning in relation to the evaluation of this patient during the treatment, with a view to providing attendance which meets her needs. For this, appropriate evaluation is necessary, as is a multi-professional service which meets this patient's needs.

In relation to the means obtained in the present study, one can verify that there was a decrease in the means of all the scales in the different points of the application of the instrument, evidencing that there is worsening of the Health-Related Quality of Life during the course of the radiotherapy treatment.

The scores of the FACT H\&N instrument vary from 1 to 5 ; the higher the score, therefore, the better the positivity in relation to the domain measured. In spite of the means of the subscales decreasing during the course of the treatment, we found high means among the domains of physical well-being and emotional well-being, as the scores of the same are close to 5 . Because of this, we can infer that there is low impact of the disease and of the treatment in these domains.

Although the domain of physical well-being was above the mean, we ascertained that it was the domain which declined most during the course of the radiotherapy treatment. The items which compose this domain are as follows: "I have no energy", "I become nauseous", "Because of my physical condition, it is difficult for me to meet the needs of my family", "I am in pain", "The side effects of the treatment annoy me", "I feel ill", "I have to lie down during the day". As we can observe, the items which make up this domain 
are related to the side effects resulting from the treatment.

It is common for symptoms of nausea, vomiting, pain, loss of appetite and constipation to occur during the treatment, while at the end of treatment, the greater occurrence of fatigue, dyspnea and diarrhea is common $^{(13)}$. This explains the decline of the means, as the treatment is undertaken, the side effects appear.

The domain of emotional well-being is the most affected, as it is below the mean in the three applications of the instrument, although it maintains the same mean in the second and third applications, demonstrating this domain's negative impact for Health-Related Quality of Life.

The domain of functional well-being is subdivided in 7 items, mainly: "I can work", "I feel fulfilled with my work", "I can feel pleasure in living", "I accept my disease", "I sleep well”, "I enjoy the things which I normally do to have fun", "I am satisfied with my quality of life at the moment". All these items from the functional well-being scale have a negative impact on the Health-Related Quality of Life of the patients interviewed.

The domain of functional well-being is related to aspects which influence the patient's daily activities. The anatomical location itself causes the malignant neoplasias of the head and neck to entail significant changes in the vital functions related to eating, communication and social interaction, generally leading to some degree of dysfunction in their daily life ${ }^{(17)}$.

The reduction of Health-Related Quality of Life during the treatment can be explained by the presence of the symptoms which are specific to the treatment of cancer, as has also been observed in other studies $^{(9,12-13)}$, which evidenced that the reduction of the same is impaired over the course of the treatment, either because of the disease itself, or because of the symptoms resulting from the treatment, and also because of the expectations regarding the same.

We can ascertain in this study that the radiotherapy treatment interferes negatively in the patients' Health-Related Quality of Life. There are various related factors in this influence, including the physical and psychological side effects, in addition to the interference in the social life of the patient, who has her daily life interrupted for several weeks, due to the treatment which requires that she receive daily doses of radiation.

One review study aimed to investigate the experience of patients with cancer of the head and neck who underwent radiotherapy treatment, and ascertained that, in addition to the physical symptoms felt by the patients, the experience of being in a machine for the treatment creates feelings of stress, due to being in a strange and uncomfortable environment - besides the anxiety experienced by them because of the uncertainty of the treatment ${ }^{18)}$.

In the light of the above, we must consider the importance of the multi and interdisciplinary practice, in order to provide appropriate and efficacious treatment for the patient. The attendance for the oncological patients must be undertaken in a systemic context, encompassing the physical, emotional, sociocultural and spiritual aspects ${ }^{(19)}$.

For this, it is necessary to consider the perspective of Comprehensive Care, which involves patients and family members, in order to investigate the specific requirements of each situation, always centered on the improvement of the quality of the oncological care ${ }^{(19)}$ and aiming, above all, for the patient to have good Health-Related Quality of Life throughout her treatment.

\section{Conclusion}

The cancers of the head and neck affect regions related to the physiological functions, leading to the risk of the patient experiencing functional changes such as problems of impaired respiration, swallowing and verbal communication. Besides the functional changes, there are also esthetic changes, which can lead to social isolation, negatively affecting these patients' Health-Related Quality of Life, and adherence 
to the treatment may also be impaired.

Treatments for this type of cancer can also be aggressive and often mutilating, as is the case of surgery. Other common treatments for this type of cancer are radiotherapy and chemotherapy, which are used as adjuvant and auxiliary in the prevention of metastases and improvement of the patients' survival.

Radiotherapy is a treatment which allows the integrity of the organs, however, the patients may experience any of numerous side effects which negatively affect their Health-Related Quality of Life.

This study evidenced that the patients' HealthRelated Quality of Life was impaired during the course of the treatment, which may be explained by the appearance of the symptoms caused by the same. As a result, the treatment becomes more efficacious once the symptoms have been identified and evaluated during the course of the treatment by the health team, allowing comprehensive care which provides interventions according to the patient's needs, so as to improve her well-being and health-related quality of life.

This study's results made it possible to identify the importance of the evaluation of Health-Related Quality of Life by the health professionals, such that they may detect the patient's main needs during the course of the radiotherapy treatment, and thus seek strategies which minimize the symptoms, so as to improve the Health-Related Quality of Life during her treatment.

\section{Collaborations}

Paula JM participated in the development, collection and analysis of the data, and in the editing and critical analysis of the article. Sawada NO contributed in the conception, analysis, data interpretation, editing of the article, and final approval of the version to be published.

\section{References}

1. Instituto Nacional de Câncer José Alencar Gomes da Silva. Coordenação Geral de Ações Estratégicas, Coordenação de Prevenção e Vigilância. Estimativa 2014: incidência de câncer no Brasil. Rio de Janeiro: INCA; 2011.

2. Galbiatti ALS, Ruiz MT, Maniglia JV, Raposo LS, Pavarino-Bertelli EC, Goloni-Bertollo EM. Head and neck cancer: genetic polymorphisms and folate metabolism. Braz J Otorhinolaryngol. 2012; 78(1):132-9.

3. Marcu LG, Yeoh E. A review of risk factors and genetic alterations in head and neck carcinogenesis and implications for current and future approaches to treatment. J Cancer Res Clin Oncol. 2009; 135(10):1303-14.

4. Lopes A, Iyeyasu H, Castro RMRPS. Oncologia para a graduação. São Paulo: Tecmedd; 2008.

5. Lôbo ALG, Martins GB. Consequências da radioterapia na região de cabeça e pescoço: uma revisão da literatura. Rev Port Estomatol Med Dent Cir Maxilofac. 2009; 50:251-5.

6. Bragante KC, Nascimento DM, Motta NW. Avaliação dos efeitos agudos da radioterapia sobre os movimentos mandibulares de pacientes com câncer de cabeça e pescoço. Rev Bras Fisioter. 2012; 16(2):141-7.

7. Leal LB, Moura IH, Carvalho RBN, Leal NTB, Silva AQ, Silva ARV. Related quality of life health of people with type 2 diabetes mellitus. Rev Rene. 2014; 15(4):676-82.

8. Kagawa-Singer M, Padilla GV, Ashing-Giwa K. Health-related quality of life and culture. Semin Oncol Nurs. 2010; 26(1):59-67.

9. Sawada NO, Paula JM, Sonobe HM, Zago MMF, Guerrero GP, Nicolussi AC. Depression, fatigue, and health-related quality of life in head and neck cancer patients: a prospective pilot study. Support Care Cancer.2012; 2:1-7.

10. Instituto Nacional de Câncer. TNM: classificação de tumores malignos. Rio de Janeiro: INCA; 2004. 
11. Paula JM, Sonobe HM, Nicolussi AC, Zago MMF, Sawada NO. Symptoms of depression in patients with cancer of the head and neck undergoing radiotherapy treatment: a prospective study. Rev Latino-Am Enfermagem. 2012; 20(2):362-8.

12. Sommerfeld CE, Garcia Andrade MG, Santiago SM, Takahiro CC, Machado CG et al. Quality of life in patients with head and neck câncer. Rev Bras Cir Cabeça Pescoço. 2012; 41(4):172-7.

13. Melo Filho MR, Rocha BA, Pires MBO, Fonseca ES, Freitas EM, Martelli JH et al . Qualidade de vida de pacientes com carcinoma em cabeça e pescoço. Braz J Otorhinolaryngol. 2013; 79(1):82-8.

14. Paiva MDEB, Biase RCCG, Moraes JJC, Ângelo AR, Honorato MCTM. Oral complications of câncer therapy. Arq Odontol. 2010; 46(1):48-55.

15. Epstein JB, Thariat J, Bensadoun RJ, Barasch A, Murphy BA, Kolnick L, et al. Oral Complications of cancer and cancer therapy from cancer treatment to survivorship. CA Cancer J Clin. 2012; 62:40022.
16. Maciel CTV, Leite ICG, Soares RC, Campos RJDS. Análise da qualidade de vida dos pacientes com câncer de laringe em hospital de referência na região Sudeste do Brasil. Rev CEFAC. 2013; 15(4):932-40.

17. Zandonai AP, Cardozo FMC, Nieto ING, Sawada NO. Qualidade de vida nos pacientes oncológicos: revisão integrativa da literatura latino-americana. Rev Eletr Enf. [periódico na Internet]. 2010 [citado 2014 nov 4]; 12(3):554-61. Disponível em: http:// www.fen.ufg.br/revista/v12/n3/v12n3a20.htm

18. Donovan M, Glackin M. The lived experience of patients receiving radiotherapy for head and neck cancer: a literature review. Int J Palliat Nurs. 2012; 18(9):448-55.

19. Sales CA, Matos PCB, Mendonça DPR, Marcon SS. Cuidar de um familiar com câncer: o impacto no cotidiano de vida do cuidador. Rev Eletr Enf. [periódico na Internet]. 2010 [citado 2014 nov 4]; 12(4):616-21. Disponível em: http://www.fen. ufg.br/fen_revista/v12/n4/pdf/v12n4a04.pdf 